\title{
ARGUMENTAÇÃO ÉTICA: campanha educativa do Jornal do Ônibus
}

\author{
Ethic argumentation: educational campaign of Jornal do Ônibus \\ (bus' newspaper)
}

\author{
Maria Teresa Cardoso de Campos ${ }^{[a]}$, Vanessa Madrona Moreira Salles ${ }^{[b]}$, \\ Marília de Lima Fonseca ${ }^{[c]}$, Daniel Fortes de Figueiredo ${ }^{[\mathrm{d}]}$
}

\footnotetext{
[a] Coordenadora, Mestre em Filosofia pela Universidade Federal de Minas Gerais (UFMG), professora no Centro Universitário de Belo Horizonte (Uni-BH), Belo Horizonte, MG - Brasil, e-mail: teresa_campos@hotmail.com

${ }^{\left[{ }^{b]}\right.}$ Colaboradora, Doutora em Filosofia pela Universidade de São Paulo (USP), professora no Centro Universitário de Belo Horizonte (Uni-BH), Belo Horizonte, MG - Brasil, e-mail: vanessasalles@uol.com.br

${ }^{[c]}$ Bolsista, Graduada em Comunicação Social, Publicidade e Propaganda pelo Centro Universitário de Belo Horizonte (Uni-BH), Belo Horizonte, MG - Brasil, e-mail: marilia_limafonseca@yahoo.com.br

[d]Bolsista, Aluno de Comunicação Social, Publicidade e Propaganda no Centro Universitário de Belo Horizonte (Uni-BH), Belo Horizonte, MG - Brasil, e-mail: danfortes@gmail.com
}

\begin{abstract}
Resumo
A campanha educativa Gentileza urbana é... faz parte do Jornal do Ônibus, um boletim informativo afixado nos coletivos urbanos da região metropolitana da cidade de Belo Horizonte. Neste trabalho, pretendemos entender qual estratégia é usada nesta campanha, para atingir seu objetivo de persuadir os usuários de transporte coletivo a comportarem-se de maneira moralmente positiva. Através da técnica de pesquisa Análise Argumentativa, que se mostrou apropriada para investigar a argumentação desenvolvida em um meio de comunicação, percebemos que é utilizada uma argumentação ética, cujos elementos (dados, proposições, garantias e apoios) se mostram adequados à finalidade pretendida. Além disso, observamos que a campanha tem um caráter universalista, ou seja, se opõe a uma visão relativista da ética. Segundo uma perspectiva kantiana, podemos dizer que os criadores da campanha consideram que os enunciados devem ser leis de abrangência universal, ou seja, regras gerais que devem ser cumpridas por todo e qualquer usuário de transporte coletivo, que são tornadas públicas no jornal.
\end{abstract}

Palavras-chave: Ética. Argumentação. Campanha educativa. 


\begin{abstract}
The educational campaign Gentileza urbana é... (Urban carefulness is to ...) is part of the Jornal do Onibus (Bus' newspaper), an informative report that is fixed in the urban public transports of the metropolitan region in the city of Belo Horizonte. In this work we try to understand the strategy that is used in this campaign, to hit its objective of persuading the users of this transportation to behave in a morally positive way. Through the research technique of Argumentation Analysis, is shown as appropriate to investigate developed argumentation in a media of communication, we realize that an ethic argumentation was used, whose elements (data, propositions, guaranties and support) are shown as adequate to the proposed finality. Moreover, we observe that the campaign has a universal character, and in other words, opposes a relative vision of ethics. According to a perspective of Kant, we can say that the creators of the campaign consider that the enunciations should be laws of universal embracement, or in other words, general rules that should be fulfilled by every and any user of collective transport, which are made public in the journal.
\end{abstract}

Keywords: Ethic. Argumentation. Educational campaign.

\section{INTRODUÇÃO}

O Jornal do Onibus é um boletim quinzenal, em formato cartaz, colorido e ilustrado, afixado regularmente nos coletivos urbanos que circulam na região metropolitana da cidade de Belo Horizonte. Publicado pela Prefeitura e pela BHTRANS, Empresa de Transportes e Trânsito de Belo Horizonte, o periódico surgiu em 1994, transmitindo informações de interesse público e contando com grande aceitação por parte dos passageiros. De acordo com pesquisa realizada pelo Doxa Instituto, em junho de 2007, e veiculada no próprio informativo, na edição 325 , ele é conhecido por $77 \%$ dos usuários e $82 \%$ consideram a maioria das suas informações importantes (BELO HORIZONTE, 2007a).

$\mathrm{Na}$ parte inferior, o boletim divulga uma campanha intitulada Gentileza urbana é...., a qual segue um padrão linguístico e imagético, ou seja, possui sempre formato retangular, e apresenta, em todas as edições, o enunciado de uma regra, acompanhada pelo desenho de uma situação que se passa no interior de um ônibus ou próximo a ele, além dos nomes dos usuários que a sugeriram e seus respectivos bairros. ${ }^{1}$
Nesta pesquisa pretendemos entender qual a estratégia usada na campanha para atingir seu objetivo de persuadir os usuários de transporte coletivo a comportarem-se de maneira moralmente positiva. Nossa hipótese é de que a campanha utiliza uma argumentação ética, embasada por princípios coerentes com o seu objetivo.

\section{Uma análise argumentativa}

Para compor a amostra da investigação, recortamos vinte e seis edições do Jornal do Onibus, do n. 256, de outubro de 2004, ao n. 282, de novembro de 2005 (BELO HORIZONTE, 2007b). A técnica de pesquisa utilizada é a da Análise Argumentativa, cujos princípios foram apresentados em Pesquisa qualitativa com texto, imagem e som: um manual prático, por Miltos Liakopoulos (2002), baseados na teoria da argumentação de Stephen Toulmin (1958), exposta na obra The uses of arguments. Aquele autor explica que a Análise Argumentativa é uma técnica que se mostra apropriada para investigar a argumentação da era dos meios de comunicação de massa e da propaganda, que envolve maior diversidade e

\footnotetext{
1 Nas edições analisadas, existia também o símbolo da campanha, que depois foi excluído. Este era composto por uma haste que sustentava um quadro, no qual havia o título da campanha e o desenho de vários prédios, com uma montanha ao fundo. Ele sugeria uma placa de parada de ônibus e, o desenho, a cidade de Belo Horizonte, já que a Serra do Curral é considerada o seu símbolo.
} 
quantidade de atores. Para definir argumentação, ele cita F. H. van Eemeren (2002, p. 219): "O termo argumentação se refere a uma atividade verbal ou escrita que consiste em uma série de afirmações com o objetivo de justificar, ou refutar, determinada opinião, e persuadir uma audiência."

Segundo Liakopoulos (2002, p. 220), os elementos que compõem uma argumentação são os dados, as proposições, as garantias, os apoios e as refutações. Uma proposição é uma afirmação sustentada por dados, os quais são fatos passados ou atuais. Estes antecedem a proposição e são explícitos. Entre os dados e a proposição, estão as garantias, que são necessárias para dotar o argumento de consistência, sendo implícitas. Quanto ao apoio, é geralmente explícito, aparecendo para endossar a garantia. Já as refutacõos expõem pontos que podem contestar o argumento, por isso nem sempre são necessárias, pois são capazes de comprometer o efeito persuasivo da argumentação.

No caso da campanha Gentileza urbana é..., a fonte da argumentação é a BHTRANS, a empresa que controla o trânsito e o transporte urbano de Belo Horizonte, que se vale do suporte midiático do Jornal do Onibus, para oferecer informações ao passageiro que tiver disponibilidade de dedicar alguns minutos para a leitura. O contexto do discurso argumentativo é um espaço público - o interior dos coletivos urbanos. Nesse sentido, o jornal se assemelha a um jornal mural, que distribui notícias gratuitamente a qualquer interessado. $O$ passageiro pode ser considerado um "leitor movente ou fragmentado", segundo a tipologia proposta por Lúcia Santaella, no texto "A leitura fora do livro" (2008). De acordo com a autora, ele se caracteriza por ser ágil e apressado, uma vez que se move no ritmo das grandes cidades, repleta de mídias, lendo fatias de textos. O passageiro de ônibus seria, então, duplamente movente, já que lê um boletim que contém informações concisas e muitas imagens, dentro de um veículo que está em movimento.

Quanto à estrutura do argumento, os dados são os problemas éticos que ocorrem no interior de um ônibus urbano ou próximo a ele, os quais são representados por desenhos. São estes que sugerem o texto, no caso, as normas éticas. Em outras palavras, o texto ilustra a imagem. Esses dados são relevantes para persuadir os usuários a aderirem à campanha, pois eles, muitas vezes, identificam-se com a cena da ilustração, por vivenciarem situações semelhantes. Como exemplo, vejamos o quadro n. 263. A regra "respeitar o espaço do passageiro ao lado" ilustra a seguinte situação: em um banco de ônibus, estão uma mulher e um homem sentados. Ele está assoviando, com as pernas abertas, olhando para o lado oposto à mulher. Ela está um pouco de lado, olhando para ele, carrancuda. Propositalmente o homem foi desenhado com maiores proporções, para indicar que está ocupando mais espaço que o destinado a ele. Já a posição e a fisionomia carregada da mulher mostram sua insatisfação pelo incômodo causado pelo homem.

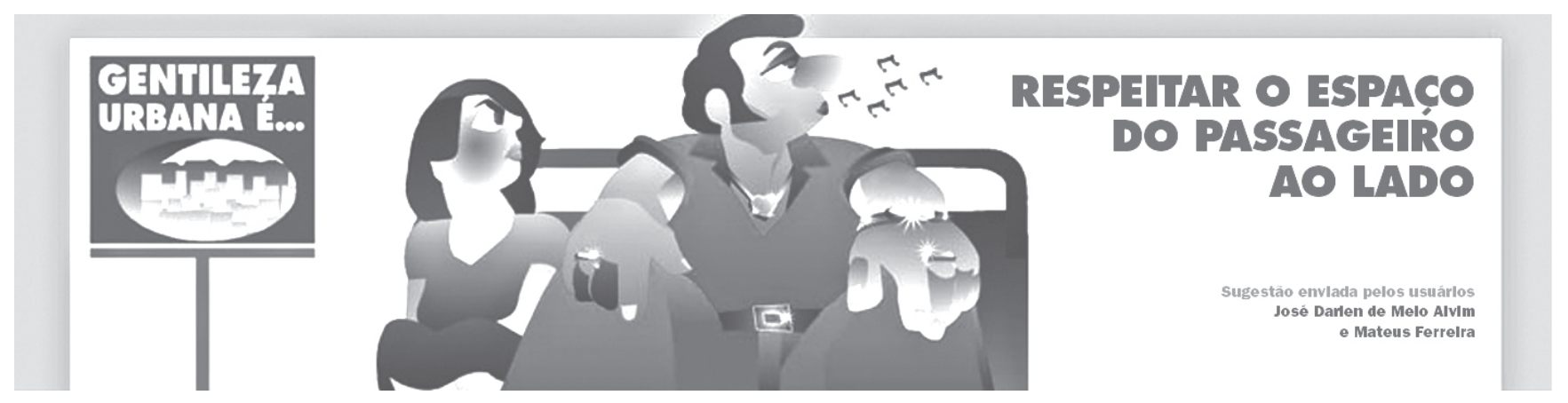

FIGURA 1 - Exemplo da seção Gentileza urbana é...

Fonte: Jornal do Ônibus, n. 263 - BHTRANS, Prefeitura de Belo Horizonte (ilustração: Adão Rodrigues). 
Na campanha, as proposições do argumento são os enunciados, isto é, as regras apresentadas, como, por exemplo, "Sacudir sombrinhas e guardachuvas antes de embarcar no ônibus", "Respeitar o espaço do passageiro ao lado" e "Dar passagem dentro do ônibus para o usuário que deseja desembarcar" . Essas regras se dividem em imperativos afirmativos e negativos, ou seja, prescrevem ordens que devem ser cumpridas e outras que não devem ser realizadas. Em outras palavras, algumas objetivam incentivar ações consideradas morais ("corretas") e outras visam coibir ações consideradas imorais ("incorretas"), pela sociedade brasileira.

É ainda possível classificá-las nas seguintes categorias: localização: existem aquelas que direcionam o comportamento do usuário no interior do ônibus e outras o seu comportamento fora do coletivo; condição temporal: indicam o momento em que é apropriado cumprir a regra; envolvidos: algumas envolvem outro usuário e outras têm um sentido mais geral, dizendo respeito à coletividade, à cidade, ao meio ambiente; ambiente: algumas não devem ser respeitadas exclusivamente no ambiente que envolve o coletivo urbano, mas em qualquer espaço; livre trânsito: apoiam a livre circulação das pessoas com dificuldades de locomoção; bem-estar: dizem respeito à saúde; conforto: visam permitir maior comodidade no interior do ônibus; e, finalmente, etiqueta: objetivam tornar as relações interpessoais mais agradáveis.

Uma teoria ética que nos permite perceber como os criadores da campanha e os usuários que enviam sugestões a ela compreendem esses enunciados é aquela desenvolvida por Immanuel Kant. ${ }^{3}$
Para Kant, a moral se funda na razão. Não podem constituir princípio moral as inclinações pessoais, o amor a si próprio e ao próximo, a busca da felicidade e do prazer. O núcleo da moral reside no dever, ou seja, no respeito à lei moral. Uma ação é considerada moral se é guiada pelo dever, e não por inclinações e sentimentos. Do mesmo modo, a finalidade de uma ação, ou seja, aonde se quer chegar, não determina o seu valor moral. Vale, por exemplo, a honestidade que é por dever e não aquela que é movida por interesse. Para saber se está agindo corretamente, o homem deve se perguntar se a sua ação pode ser generalizável, isto é, se pode tornar-se válida para todos: uma lei universal. Este é o "imperativo categórico", um procedimento que permite ao agente distinguir se deve ou não agir de uma determinada maneira e faz do homem um legislador universal. Uma das suas formulações é a seguinte: "Age apenas segundo uma máxima tal que possas ao mesmo tempo querer que ela se torne lei universal" (KANT, 1980, p. 129). Na perspectiva kantiana, deve-se levar ainda em conta que é preciso compreender o homem como um fim em si e não como um meio, o que significa respeitar os outros como pessoas e não como instrumentos úteis para se alcançar uma finalidade.

A ética kantiana é universalista, opondose à maneira contemporânea de se pensar a moralidade. É nesse sentido que o estudioso Sérgio Paulo Rouanet afirma (1992, p. 153):

Vivemos num mundo onde não existe nenhuma fé na possibilidade de fundar objetivamente a escolha moral. [...] E vivemos numa época dominada cada vez mais pelos

\footnotetext{
2 As demais regras da amostra são: não jogar objetos ou lixo pelas janelas dos ônibus; ao conversar no interior do ônibus, falar em tom de voz baixo; ajudar os usuários, carregando embrulhos, sacolas, cadernos e livros; não congestionar a passagem pela roleta. Passagem na mão não atrasa a lotação; dar espaço para quem estiver em pé segurar no corrimão; ser cortês e cumprimentar o motorista e o agente de bordo ao embarcar no ônibus; se oferecer para levar sacolas, cadernos e bolsas das pessoas que estão de pé; antes de embarcar no ônibus, aguardar o desembarque dos passageiros; não assentar ou aglomerar nos degraus do ônibus, impedindo o embarque e desembarque; separar o dinheiro ou cartão BHBUS com antecedência, antes de desembarcar; respeitar os lugares reservados aos idosos, pessoas com deficiências e grávidas; não arremessar objetos pelas janelas dos coletivos; fechar as janelas nos períodos de chuva para não molhar os assentos; Entrar devagar no ônibus, sem empurrar os demais usuários; pedir licença à pessoa que está sentada no canto para abrir a janela; saudar e respeitar motoristas e agentes de bordo; ao entrar no ônibus, retirar mochilas e bolsas das costas; não fumar nas filas de embarque dos ônibus. antes de embarcar, aguardar o desembarque de idosos, gestantes e pessoas com deficiência; respeitar os lugares reservados aos idosos e pessoas com deficiência ou mobilidade reduzida; ocupar os espaços na parte traseira do ônibus, permitindo o embarque dos demais usuários; não jogar lixo pela janela. utilize as lixeiras dentro dos ônibus; nos dias de chuva, colocar a sombrinha em uma sacola para não molhar os passageiros.

Kant explicita a sua teoria ética na "Fundamentação da metafísica dos costumes”, de 1785, e na obra Crítica da razão prática, de 1788.
}

Rev. Estud. Comun., Curitiba, v. 10, n. 21, p. 85-90, jan./abr. 2009 
diversos particularismos, que negam a existência de verdades universais ou de uma moralidade universal.

A partir dessas considerações, é possível perceber que a campanha Gentileza urbana é... tem um caráter universalista. Segundo uma perspectiva kantiana, podemos dizer que os criadores da campanha consideram que os enunciados devem ser leis de abrangência universal, ou seja, regras gerais que devem ser cumpridas por todo e qualquer usuário de transporte coletivo, tornadas públicas no jornal. Já do ponto de vista do usuário que encaminha uma sugestão, a regra enviada é uma máxima que ele pretende que se converta em lei universal.

Em relação às garantias, elas relacionamse com a natureza dos enunciados, ou seja, das proposições. Esses enunciados constituem normas éticas, e o que nos autoriza a compreendê-los dessa forma é que são regras que dizem como deve ser o bom comportamento, o que significa, no caso estudado, serem apropriadas para o ambiente do transporte público. Como se sabe, a ética tem como objetivo refletir sobre a moral, ou seja, o conjunto de normas que disciplina a conduta dos indivíduos que se relacionam em sociedade, sendo que o bem é o valor que subjaz a tais normas. Recorremos a Nicola Abbagnano (1998, p. 107) para explicar o termo "bem":

Dessa esfera do significado geral, pela qual a palavra se refere a tudo o que tem um valor qualquer, pode-se recortar a esfera do significado específico, em que a palavra se refere particularmente ao domínio da moralidade, isto é, dos mores, da conduta, dos comportamentos humanos intersubjetivos, designando, assim, o valor específico de tais comportamentos.

Uma garantia identificada é o significado da palavra "gentileza", que pode remeter ao valor da urbanidade, ou seja, a cortesia que se expressa no convívio social. Uma definição de "gentileza", no dicionário de Caldas Aulete (1964, p. 1928) é "Ação de valor; ação nobre, ilustre; cortesia; urbanidade; valor, esforço, valentia". Isto estaria em consonância com o sentido educativo da campanha, que é dirigida a usuários de coletivos urbanos, os quais necessitam obrigatoriamente conviver com muitas pessoas e, para que isso seja possível, precisam observar o cumprimento de várias normas de comportamento.
Outra garantia percebida é o fato de que o Jornal do Ônibus se apropriou do termo "Gentileza urbana", originalmente criado pelo Instituto dos Arquitetos do Brasil, de Minas Gerais (IAB/MG), em 1993, para nomear um prêmio que homenageia as iniciativas positivas, realizadas em prol da cidade de Belo Horizonte (SANTOS, 2007). Observamos, então, que uma iniciativa que tem em vista o bem comum, gerou outra da mesma natureza.

Outro elemento do texto argumentativo é o apoio e, na campanha, um deles é a frase "Gentileza urbana é...". Ela está presente em todas as edições e, desse modo, os passageiros se deparam com a frase inúmeras vezes. Como se sabe, na área da propaganda, a repetição de uma mensagem tem grande poder persuasivo. Esta tática é, inclusive, muito utilizada na propaganda política e, segundo Rabaça e Barbosa (1978, p. 379), no Dicionário de Comunicação, "consiste em repetir infatigavelmente os temas principais, até que a nova idéia se transforme em lugar-comum, em verdade definitiva que todos aceitam como dogma."

As sugestões dos usuários também são apoios, porque promovem identificação dos passageiros com asideias transmitidas pela campanha. Elas indicam que são eles próprios que reivindicam a existência de regras éticas para regular o comportamento de quem viaja em um ônibus urbano.

Finalmente, percebemos que no discurso argumentativo desenvolvido na campanha não coube usar a refutação, uma vez que não se trata de um debate e sim de uma propaganda e, nesse tipo de argumentação, só tem lugar um texto afirmativo e impositivo.

\section{Persuasão e ética}

Tendo em vista o objetivo educativo da campanha Gentileza urbana é... , que consiste em persuadir os passageiros de transporte coletivo a agir eticamente, observamos que é utilizada uma argumentação ética, cujos elementos se mostram adequados à finalidade pretendida.

As proposições visam a promover a conscientização da população, que faz uso cotidianamente do ônibus, sobre a prática do respeito mútuo e da convivência social. Elas constituem regras éticas, dirigidas aos usuários de forma impositiva, pois são imperativos, e aparecem como normas gerais, que devem ser respeitadas, indistintamente, por todos; o que thes confere grande capacidade persuasiva. Os dados são os problemas éticos enfrentadospelos usuários 
no dia a dia. Tais questões são representadas por ilustrações sugestivas, que reforçam a competência das regras de influenciar os passageiros. As garantias relacionam-se com a natureza ética dos enunciados, oferecendo-lhes mais consistênciae, consequentemente, maior força persuasiva. Uma delas é o conceito de "gentileza", que alude à urbanidade. Outra seria que em Belo Horizonte havia sido instituído um prêmio denominado "Gentilezaurbana", peloIAB/MG. Quanto ao apoio, encontramos a frase "Gentileza urbana é...", que se repete em toda a campanha, sendo a redundância um fatorsabidamentepersuasivo; etambém as sugestões dos usuários, que ao proporcionar identificação destes com o tema da campanha, contribui para convencê-los a seguir o que lhes é proposto.

A Gentileza urbana é... se opõe a uma visão extremamente relativista da ética que diante da evidência das diferenças culturais, históricas, geográficas, entre outras, rende-se à ideia de que qualquer forma de comportamento é válida. A campanha concebe que a ética deve se sustentar na racionalidade. Esta não deve existir apenas como possibilidade, mas como realidade que pode dar dignidade à vida humana.

\section{CONSIDERAÇÕES FINAIS}

Percebemos o espaço Gentileza urbana é... como uma iniciativa rara, pois geralmente a mídia é acusada de não utilizar seu poderoso poder de persuasão para modelar atitudes e comportamentos a serviço do bem comum. Ela é acusada de ser antiética, ou seja, de não se ater aos princípios e às normas que promovem o progresso moral dos homens, e também de não se preocupar em educar moralmente o público. Como afirma Cicilia Peruzzo (2002, p. 75), no artigo "Ética, liberdade de imprensa, democracia e cidadania": "A ética é constantemente violada no dia-a-dia das várias áreas da comunicação social no Brasil: da imprensa à publicidade; das relações públicas aos programas de entretenimento e aos de jornalismo." Notamos, no entanto, que a campanha Gentileza urbana é... , ao contrário, é uma iniciativa que pretende chamar a atenção de seu público para agir positivamente em benefício das relações interpessoais e, ao mesmo tempo, criticar os procedimentos e as práticas que se contrapõem aos valores que embasam a cidadania. E isto é possível, segundo nosso ponto de vista, por causa da utilização de uma argumentação bem construída, que tem na ética sua sustentação.

\section{REFERÊNCIAS}

ABBAGnAnO, N. Dicionário de filosofia. 3. ed. rev. e ampl. São Paulo: Martins Fontes, 1998.

AULETE, C. Dicionário contemporâneo da Língua Portuguesa. 2. ed. rev. aum. Rio de Janeiro: Delta, 1964.

BELO HORIZONTE. Prefeitura Municipal. Empresa de Transportes e Trânsito de Belo Horizonte. Jornal do Ônibus, Belo Horizonte, Informativo, n. 325, set. 2007 a.

BELO HORIZONTE. Prefeitura Municipal. Empresa de Transportes e Trânsito de Belo Horizonte. Sala de Imprensa. Jornal do Ônibus, Disponível em: <http:/ /www.bhtrans.pbh.gov.br>. Acesso em: 06 fev. 2007b.

CRAMPE-CASNABET, M. Kant: uma revolução filosófica. Rio de Janeiro: Jorge Zahar, 1994.

KANT, I. Fundamentação da metafísica dos costumes. In: Kant II. São Paulo: Abril Cultural, 1980. p. 101-162.

LIAKOPOULOS, M. Análise argumentativa. In: BAUER, M. W.; GASKELL, G. (Ed.). Pesquisa qualitativa com texto, imagem e som: um manual prático. 3. ed. Petrópolis: Vozes, 2002. p. 218-243.

PERUZZO, C. M. K. Ética, liberdade de imprensa, democracia e cidadania. Revista Brasileira de Ciências da Comunicação, São Paulo, v. 25, n. 2, p. 71-88, 2002.

RABAÇA, C. A.; BARBOSA, G. Dicionário de comunicação. Rio de Janeiro: Codecri, 1978.

ROUANET, S. P. Dilemas da moral iluminista. In: NOVAES, A. Ética. São Paulo: Companhia das Letras, 1992. p. 149-162.

SANTAELLA, L. A leitura fora do livro. Disponível em: <http://www.pucsp.br/pos/cos/epe/mostra/ santaell.htm>. Acesso em: 30 jun. 2008.

SANTOS, P. Bom lugar de estar. Disponível em: $<$ http://vidasimples.abril.com.br/subhomes/morar/ morar_237887.shtml>. Acesso em: 02 maio 2007.

TOULMin, S. E. The uses of arguments. Cambridge: Cambridge University Press, 1958.

Recebido: 18/11/2008

Received: 11/18/2008

Aprovado: 13/04/2009

Approved: 04/13/2009

Revisado: 03/11/2009

Reviewed: 11/03/2009

Rev. Estud. Comun., Curitiba, v. 10, n. 21, p. 85-90, jan./abr. 2009 